\title{
Case Report on Von Recklinghausen Disease - An Array of Challenges for the Anaesthesiologist in the Era of COVID Pandemic
}

\author{
Dr. P. Veena ${ }^{1}$, Dr. Mariam Joan Varghese ${ }^{2}$ \\ ${ }^{1}$ Former Assistant professor, Department of Anaesthesiology Dr S.M.C.S.I Medical College Karakonam, Thiruvananthapuram, Kerala, \\ India \\ Present Assistant Professor, Department of Anaesthesiology, SUTAMS, Thiruvananthapuram, kerala, India \\ (SUTAMS -SreeUthradomThirunal Academy Of Medical Sciences, Thiruvananthapuram) \\ ${ }^{2}$ Junior Resident, Department of Anaesthesiology, Dr S. M. C. S. I Medical college, Thiruvananthapuram, Kerala, India
}

\begin{abstract}
Von Recklinghausen disease is an autosominal dominant disease with a wide spectrum of multisystem involvement. Neurofibromas are the characteristic lesions associated with important anaesthetic considerations, mainly when neurofibromas occur in the oropharynx and larynx, leading to difficult laryngoscopy and tracheal intubation. We describe the anaesthetic management of a patient with NF1 under general anaesthesia for Total abdominal hysterectomy.
\end{abstract}

Keywords: Neurofibroma, Neurofibromatoses, Rapid sequence Induction, Airway management, General Anaesthesia, Heat and moisture exchanger (HME) filter

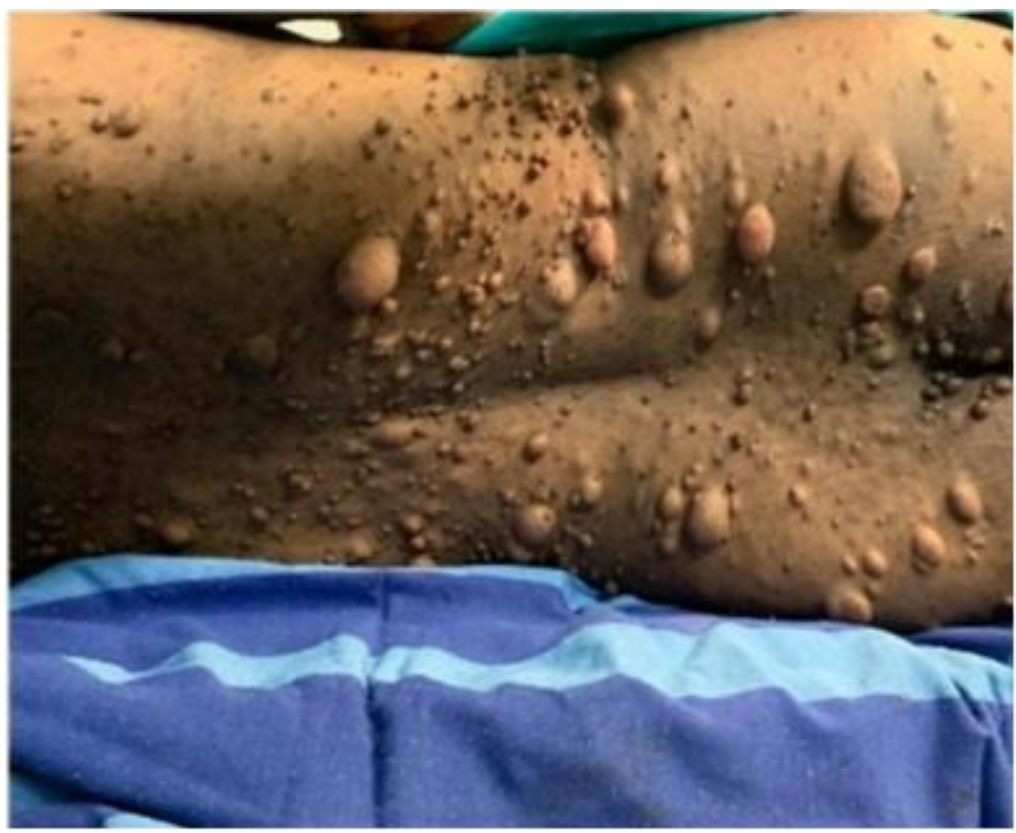

\section{Introduction}

Von recklinghausen disease or neurofibromatosis1 (NF1) is an autosomal dominant disorder characterized by the propensity to form ectodermal and mesodermal tissue tumours, affecting primarily the nervous system and the skin. Friedrich Recklinghausen identified the origin of the tumours in the nervous tissue in The pathophysiology is characterized by a mutation of the NF1 gene located on chromosome 17q11.2, responsible for secreting neurofibromin, a protein that inhibitsabnormal cell growth. The clinical spectrum of this disorder is quite broad, characterized mainly by skin neurofibromata and café-aulait spots as well as multiple system involvement.

\section{Case Report}

We are reporting a case of 50 year old $56 \mathrm{~kg}$ patient who is a diagnosed case of von Recklinghausen neurofibromatosis for the past 35 years. She presented with abnormal uterine bleeding for the past 6 months requiring multiple blood transfusions and Anemia correction. Upon investigation she was diagnosed to have multiple uterine fibroids and was initially managed conservatively later posted for an elective total abdominal hysterectomy.

She also gave history of previous lower segment caesarean section under spinal anaesthesia 35years back which went uneventful as the neurofibromas on back were very small in size. However cutaneous neurofibromas showed a

Volume 10 Issue 4, April 2021 www.ijsr.net 
progressive growth in number as well as size with increasing age. Patient is also hypothyroid since past 12 years onoweuthyroid with medication. Rest of the history was unremarkable except for history of snoring not associated with Apneic episodes.

On examination revealed multiple and diffuse neurofibromas all over her body more over the spine and extremities.

Airway examination revealed an anticipated difficult airway with buck tooth, Mallampatticlass 3, short neck and with normal temperomandibular joint movement. Airentry was equal on both sides. Blood investigations were normal. Chest Xray revealed cardiomegaly. Xray spine was normal.

In view of cutaneous neurofibromas, she was sent for a Medical neurology opinion and underwent MRI brain and spine which revealed unidentified bright objects as seen with NF-1 in globuspallidus.MRI spine revealed diffuse bulge of C5-C6 with trade neural foraminal narrowing with mild diffuse bulge in $\mathrm{C} 4-\mathrm{C} 5$.

Also underwent Nasopharyngoscopy which revealed normal vocalcords, nasopharynx, oropharynx, hypopharynx. Echocardiography revealed Grade1Diastolic dysfunction with normal Ejection fraction of $68 \%$

On Previous day of surgery high riskwritten informed consent for planned procedure (Total abdominal hysterectomy) under general anaesthesia was obtained including postop ventilatory support .

Overnight fasting advice along with $\mathrm{T}$. Ranitidine $150 \mathrm{mg}$ was advised on night before and on the morning of surgery day along with her morning dose of T.thyronorm. Owing to the presence of cutaneous neurofibromas over the back of the patient plan of General anaesthesia with rapid sequence induction was made.

On the day of surgery OT including Anaesthesia machine, difficult airway cart and emergency drugs were checkedand kept ready.

Preinduction monitors like E. C. G, Non invasive blood pressure monitor, pulseoximetry, skin temperature were connected.

Sedative premedication was avoided in view of difficult airway, However Inj. Glycopyrolate $0.01 \mathrm{mg} / \mathrm{kg}$, inj. Ondansetron $0.1 \mathrm{mg} / \mathrm{kg}$ was used as premedication after securing two wide bore cannulae and intravenous balanced salt solution. Thereafter, considering the prevailing COVID pandemic era we preoxygenated the patient with 100\%oxygen for 3 minutesat moderate flow rate with HME filter between the Y-piece and the patient's airway. The gas sampling line (for respiratory gas analysis) was attached to the machine side of the filter. In addition, a second breathing system HME filter was attached to the end of the expiratory hose where it connects to the breathing system.

Propofol based Rapid sequence inductionat as dose of $2 \mathrm{mg} / \mathrm{kg}$ and succinylscholine $2 \mathrm{mg} / \mathrm{kgI}$.V. Trachea was intubated with COETT 7ID via bougie guidance in single attempt to minimise aerosol generation .On confirming endotracheal tube placement anaesthesia was maintained with Oxygen+ Nitrous oxide + Sevoflurane (MAC 2)+intermittent injectionvecuronium $0.1 \mathrm{mg} / \mathrm{kg}$ as skeletal muscle relaxant.

Post induction monitors- Endtidal carbondioxide, urine output monitor. Analgesia was supplemented with inj. Paracetamol $15 \mathrm{mg} / \mathrm{kg}$ and inj. Fentanyl 2microgram $/ \mathrm{kg}$ based. Duration of surgery was $2 \mathrm{hrs}$ with blood loss of $400 \mathrm{ml}$ and adequate urineoutput. Total of $1500 \mathrm{ml}$ of crystalloid were given intraoperatively. On completion of surgery Anaesthesia was reversed with inj. Neostigmine $0.05 \mathrm{mg} / \mathrm{kg}$ and inj. Glycopyrolate $0.01 \mathrm{mg} / \mathrm{kg}$.

Trachea extubated with difficult airway cart standby. Vitals were stable, postoperative period was uneventful. Post extubation phonation was within normal with no neurological deficits.

\section{Discussion}

In patients with neurofibromatosis-1, anesthesiologists face additional complications and obstacles that we must consider when devising an anesthetic plan. Neurofibromatosis-1-associated complications of the central nervous, respiratory, cardiovascular, musculoskeletal, and GI and genitourinary systems all present various degrees of considerations for the anesthesiologists. Upon initial diagnosis, physicians should obtain a thorough history and physical examination to establish disease extent. The important components of the history are personal and family medical history, developmental assessment, and school performance. The important aspects of the physical examination are ophthalmologic, skin, skeletal, cardiovascular, and neurologic assessments.

Central nervous system -Anaesthetic assessment of such patients should take into account the increased incidence of epilepsy, learning difficulties and the possibility of undiagnosed CNS tumours. The most common disorder is a progressive narrowing of the internal carotid artery at the origin of the anterior and middle cerebral arteries leading to stroke.

Respiratory system - Neurofibromatosis may affect the conducting airways, lung parenchyma, the thoracic cage and the chest wall. Intrapulmonary neurofibromas are rare, usually asymptomatic and carry a good prognosis. However, they may grow to a large size resulting in cough and dyspnoea, progressive fibrosis leading to restrictive lung pattern.

Cardiovascular system - Although hypertension is the most commonly occurring cardiovascular manifestation of NF, the disease may also primarily affect the myocardium and the vasculature.

Skeletomuscular system - Thoracic spinal curvatures are common in NF1 and affect approximately $10 \%$ of NF1 patients. They appear early in childhood and often require corrective surgery Severe kyphosis, although uncommon,

\section{Volume 10 Issue 4, April 2021}


may be associated with tumours and a high risk of neurological deficit. Scoliosis with rotation may also occur and produces a reduction in lung volume, which if severe, may result in respiratory failure.

Gastrointestinal \& Genitourinary system Gastrointestinal tumours in NF1 may present with disordered gut motility, abdominal pain, haematemesis or melaena; although neurofibromas, usually affecting the jejenum or stomach, are the most common lesions, leiomyoma, ganglioneuroma and sarcoma have been described. Patients are also prone for gastroesophageal reflux disease hence, always go with rapid sequence induction for general anaesthesia.

Conflict of Interest: There is no conflict of interest from both authors.

Acknowledgement: Department of Anaesthesiology, Dr. S. M. C. S. I Medical College, Karakonam, Thiruvananthapuram, Kerala, India

\section{Conclusion}

The anesthesiologist must consider the possibility of each of the multisystemic complications associated with Von Recklinghausen disease when evaluating and managing the patient for surgical procedures.

\section{References}

[1] N. P. Hirsch, A. Murphy, J. J. Radcliffe, Neurofibromatosis: clinical presentations and anaesthetic implications, BJA: British Journal of Anaesthesia, Volume 86, Issue 4, 1 April 2001, Pages 555-564, https://doi.org/10.1093/bja/86.4.555

[2] Ghalayani P, Saberi Z, Sardari F. Neurofibromatosis type I (von Recklinghausen's disease): A family case report and literature review. Dent Res J (Isfahan). 2012;9 (4):483-488.

[3] Reynolds RL, Pineda CA. Neurofibromatosis: review and report of case. J Am Dent Assoc 1988; 117: 735-7.

Volume 10 Issue 4, April 2021 www.ijsr.net 